\title{
Eliminação antígeno-específica de células-alvo caspase-8 - suficientes ou - deficientes por linfócitos $\mathrm{TCD8}^{+}$.
}

Dissertação apresentada ao Departamento de Imunologia do Instituto de Ciências Biomédicas da Universidade de São Paulo, para obtenção do título de Mestre em Ciências.

Área de concentração: Imunologia

Orientador: Prof. Dr. João Gustavo Pessini AmaranteMendes

Versão original

São Paulo

2018 


\section{RESUMO}

SAMPAIO I. S. Eliminação antígeno-específica de células-alvo caspase-8- suficientes ou deficientes por linfócitos T CD8+. [Dissertação (Mestrado em Imunologia)]- Instituto de Ciências Biomédicas, Universidade de São Paulo, São Paulo, 2018.

A eliminação de células-alvo por linfócitos T citotóxicos (CTLs) exerce um papel importante na imunidade protetora contra patógenos e células tumorais, o que pode ser desencadeada pela ação de perforina e granzima, ou pelas interações Fas-FasL. A interação Fas-FasL promove a apoptose pela formação de DISC, que é composto pela cauda citoplasmática de Fas, a proteína adaptadora FADD e a pro-caspase-8. Nesse complexo, a caspase-8 é ativada e induz a clivagem das caspases efetoras -3 , -6 e -7 , e/ou BID - membro da família Bcl-2, desencadeando o sinal apoptótico. Recentemente, tem sido demonstrado uma correlação entre mutações no gene CASP8 de células tumorais e alta atividade citolítica, sugerindo que a deficiência em caspase-8 pode representar um mecanismo de evasão imune. Para avaliar a eliminação de células-alvo por CTLs, nós estabelecemos uma técnica de citotoxicidade in vitro utilizando blastos de camundongos OTI como células efetoras e células RMA como alvo. Nesse ensaio, as células-alvo foram marcadas e pulsadas com diferentes concentrações de peptídeo OVA e colocadas em co-cultura a diferentes razões efetora: alvo (E:A) com linfócitos OTI, estimulados por 7 dias com ConA e rIL-2. A eliminação específica foi avaliada após 16 horas de co-cultura. Como controle para avaliar a especificidade ao MHC de classe I, utilizamos as células RMA-S, uma vez que expressam níveis reduzidos desta molécula na superfície. Os resultados demonstraram que os blastos OTI tem capacidade efetora e que o ensaio estabelecido é antígeno-específico. Foi também observado que a eliminação das células RMA-S é menor em comparação com as células RMA, sendo essa diferença melhor discriminada na razão E:A de 1:8 com a concentração de 10pM de peptídeo OVA pulsado. Para avaliar o efeito da caspase- 8 na eliminação por linfócitos T CD8 $8^{+}$, células caspase-8-suficientes e - deficientes, obtidas pela técnica CRISPR-Cas9, foram utilizadas como alvo nesse ensaio. Os resultados demonstram que as células caspase- 8 -deficientes são mais resistentes à eliminação por linfócitos $\mathrm{T} \mathrm{CD} 8^{+}$, em comparação com as células caspase8-suficientes e esta diferença foi significativa na razão E:A de 1:8 com 10pM de peptídeo pulsado. Portanto, nossos dados corroboram com a ideia de que a deficiência em caspase- 8 poderia representar um mecanismo de evasão imune, principalmente na eliminação por linfócitos T CD8 ${ }^{+}$.

Palavras-chave: Caspase-8. Células RMA. Linfócitos T CD8 ${ }^{+}$. Apoptose. 


\begin{abstract}
SAMPAIO I. S. Antigen-specific elimination of caspase-8-deficient or -sufficient target cells by $\mathrm{T} \mathrm{CD}^{+}$lymphocytes. [dissertation (Master thesis in Immunology)]- Instituto de Ciências Biomédicas, Universidade de São Paulo, São Paulo, 2018.

The killing of target cells by cytotoxic T lymphocytes (CTLs) plays a major role in protective immunity to pathogens and tumor cells, which can be triggered by either the action of perforin and granzymes or FAS-FASL interactions. The Fas-FasL interaction leads to apoptosis through the formation of DISC, which is composed by the cytoplasmic tail of Fas, the adaptor protein FADD and the pro-caspase- 8 . At the complex, caspase- 8 become activated and transduce the apoptotic signal by cleaving the effector caspases-3, -6 and -7 and/or the Bcl-2 family member Bid. Recently, it has been demonstrated a correlation between mutations in CASP8 in tumors from patients with high cytolytic activity, suggesting that deficiency in caspase- 8 may represent an immune evasion mechanism. In order to assess the elimination of target cells by CTL, we have established an in vitro cytotoxic assay using as effector, blasts from OTI mice, and as target, RMA cells. In this assay, the target cells were labeled, pulsed with OVA peptide at different concentrations and then co-cultured with OTI lymphocytes, which were stimulated with ConA and rIL-2, at different effector: target (E: T) ratios. The specific elimination was evaluated after 16 hours of co-culture. As a control to assess the specificity to MHCI of our assay, RMA-S cells were used because they have reduced levels of MHCI at surface. The results have shown that OTI blasts have effector capacity and that our established assay is antigen-specific. In addition, we observed that RMA-S elimination is reduced in comparison to RMA cells. The difference between RMA and RMA-S is better detected at ratio E: T of 1:8, using 10pM of OVA peptide to pulse the cells. In order to assess the effect of caspase- 8 in the resistance to elimination by T $\mathrm{CD} 8^{+}$cells, caspase- 8 -sufficient and-deficient (obtained by CRISPR-Cas9 technique) cells were used as target in this assay. Our results demonstrate that caspase-8-deficient cells are more resistant to elimination than wild-type counterparts. This difference was better detected at 1:8 E: A ratio, using cells pulsed with $10 \mathrm{pM}$. Thus, our data suggests the deficiency in caspase- 8 results in lower elimination by $\mathrm{T} \mathrm{CD}^{+}$lymphocytes, suggesting this might represent an immune evasion mechanism.
\end{abstract}

Keywords: Caspase-8. RMA cells. T CD8 ${ }^{+}$lymphocytes. Apoptosis. 


\section{INTRODUÇÃ̃O}

O processo de morte celular é essencial para o controle homeostático e regulação do sistema imune. Há diferentes formas de morte celular, que são diferenciadas de acordo com critérios morfológicos, moleculares, aspectos funcionais ou características imunológicas (1). O processo de morte celular pode ser acidental ou regulado. A morte celular acidental é instantânea e catastrófica e ocorre em consequência à exposição a danos físicos, químicos ou mecânicos. Por outro lado, a morte celular regulada depende de uma maquinaria molecular, que pode ser modulada, operar na ausência de perturbações exógenas (exemplo: desenvolvimento de tecidos) ou originar de perturbações intrínsecas ou extrínsecas no microambiente (2).

O processo de morte celular pode ser caracterizado em diferentes tipos de acordo com as manifestações morfológicas. A morte celular do tipo I ou apoptose é caracterizada por condensação da cromatina, fragmentação nuclear, contração citoplasmática, formação de "blebs", com formação de pequenas vesículas conhecidas como corpos apoptóticos. A morte celular do tipo II ou autofagia se manifesta com vacuolização citoplasmática, resultando em captação fagocitária e degradação lisossômica. A morte celular do tipo III ou necrose é caracterizada pela ausência de envolvimento lisossomal ou fagocitário $(3,4)$

\subsection{Necroptose}

Por alguns anos, a necrose foi considerada como morte acidental. Porém, a descoberta de inibidores de necrose e evidências genéticas revelaram a existência de vias de regulação do processo de necrose (5). A elucidação deste processo de morte celular e sua regulação se deve principalmente ao entendimento da função de RIPK1 (do inglês, receptor-interacting serine/threonine-protein kinase 1) no início dos anos 2000. Até aquele momento, essa molécula era apenas associada a sobrevivência celular, inflamação e doenças. Porém, a descoberta de sua função na regulação em um processo de morte celular independente de caspase- 8 foi fundamental para a elucidação deste processo, denominado necroptose. $\mathrm{O}$ termo necroptose se refere a um processo de morte celular similar a necrose, que depende da 
atividade quinase de RIPK1. Além disso, foi também identificada outra molécula, necrostatina (Nec1), que atua na inibição de RIPK1, suprimindo o processo de necroptose (6).

A molécula RIPK1, por sua vez, interage com uma outra molécula da família RIPK, RIPK3 (do inglês, receptor-interacting serine/threonine-protein kinase 3), através de seu domínio de interação RIP de homologia (RHIM), sofrendo autofosforilação para formar um complexo denominado necrosomo. Neste complexo, a molécula MLKL (do inglês, mixedlineage kinase domain-like protein) é fosforilada por RIPK3 e forma oligômeros que se translocam para a membrana plasmática, promovendo a permeabilização desta pela interação com fosfotidilinositóis (7). MLKL é, portanto, a molécula efetora do processo de necroptose, caracterizado por inchaço celular, ruptura da membrana celular e liberação de conteúdo intracelular, induzindo respostas pró-inflamatórias (8). Foi demonstrado que o processo de necroptose ocorre em ausência da proteína caspase-8. Estudos demonstraram que camundongos deficientes em caspase- 8 apresentam letalidade na fase embrionária. Porém, esse quadro pode ser revertido pela concomitante ablação de RIPK3 (9).

Em casos em que a caspase- 8 está presente, o complexo I, formado por RIPK3 e a proteína adaptadora FADD (do inglês, Fas-associated death domain), pode desencadear outros processos. Uma vez que o receptor 1 de TNF (do inglês, tumor necrosis factor) é estimulado (TNFR1) e há a formação do complexo I, RIPK1 é ubiquitinada por inibidores celulares de apoptose (cIAPs) e pelo complexo linear de montagem de cadeia de ubiquitina (LUBAC). Consequentemente, há a ativação das vias de $\mathrm{NF}-\kappa \mathrm{B}$, resultando em aumento da sobrevivência celular, proliferação e produção de citocinas pró-inflamatórias $(10,11)$.

Em casos de estimulação adicional, o complexo I é desubiquitinado por enzimas específicas, que promovem a formação de um segundo complexo formado pelas moléculas TRADD (do inglês, TNF receptor-associated death domain), RIPK1, e FADD. Como consequência, há o recrutamento e ativação de caspase-8. A caspase- 8 ativa pode clivar diretamente as caspases executoras- caspase-3 e caspase-7 ou podem clivar a molécula BID (do inglês, BH3-interacting domain death agonist). A molécula BID promove a ativação das moléculas BAK (do inglês, BCL-2 antagonist/killer) e BAX (do inglês, BCL-2-associated X protein) e consequente permeabilização mitocondrial. Como resultado, a célula morre por apoptose $(12,13)$. Esses processos descritos estão elucidados na figura 1. 


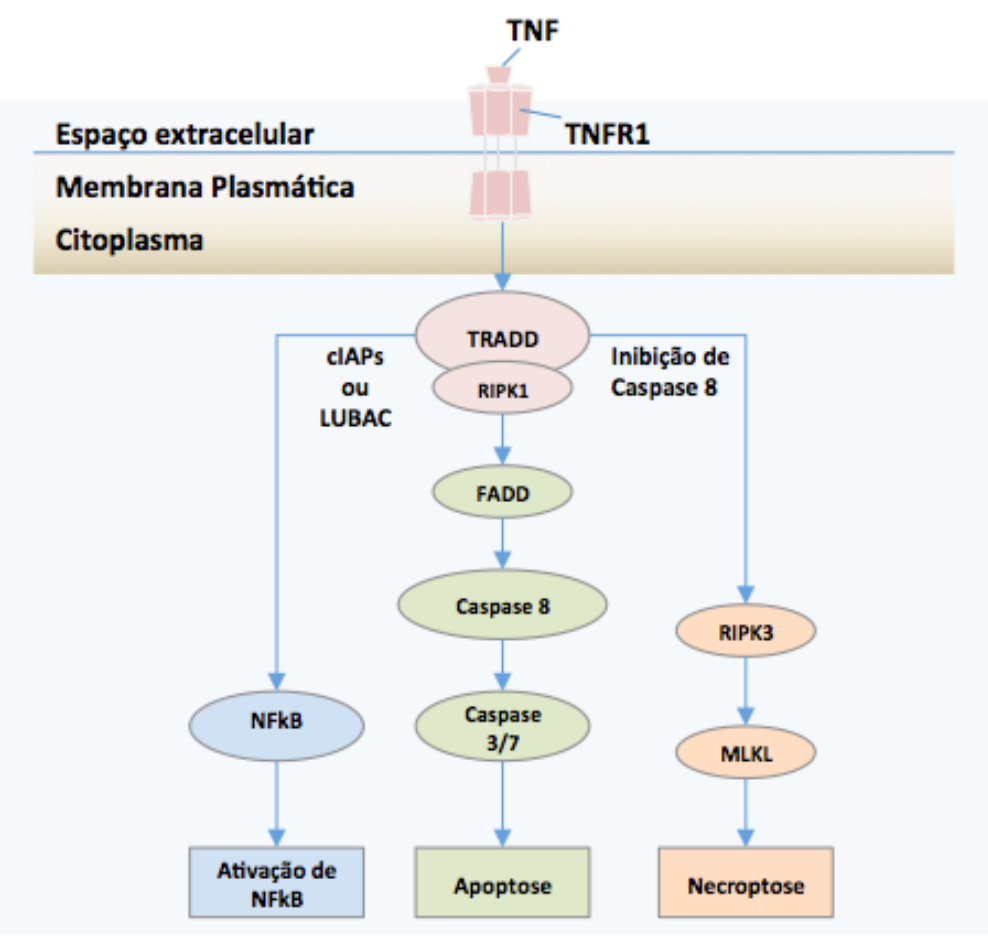

Figura 1. Mecanismos moleculares desencadeados pela estimulação do receptor de TNF e por TRADD e RIPK1. O complexo I, formado por TRADD e RIPK1, pode desencadear a ativação de NFkB após a ubiquitinação por cIAPs e LUBACs. Além disso, este complexo pode recrutar a molécula FADD em uma estimulação adicional, promovendo a ativação da caspase-8 e consequentemente das caspases efetoras $-3 / 7$, resultando na apoptose. Em situações em que a caspase8 está inibida, o complexo I ativa as moléculas RIPK3 e MLKL. A molécula MLKL transloca para a membrana plasmática, promovendo sua ruptura.

\subsection{Apoptose}

A apoptose é um processo de morte celular programada, na qual a fragmentação celular resulta na formação de corpos apoptóticos, que são fagocitados e digeridos em fagolisossomos (14-16). Nesse processo, a resposta inflamatória não é elicitada, uma vez que os conteúdos celulares não são liberados no meio extracelular, e uma eficiente fagocitose dos corpos apoptóticos impede uma possível necrose secundária. A apoptose é composta pelas vias intrínseca, extrínseca e perforina-granzima $(17,18)$.

A via intrínseca está estritamente relacionada ao balanço e controle de proteínas próe anti-apoptóticas. As proteínas da família Bcl-2 (do inglês, B-cell lymphoma 2) contribuem diretamente para o comprometimento de uma célula ao processo de apoptose (19). Dentre os membros da família Bcl-2, as proteínas BH3-only são consideradas iniciadoras do processo de apoptose, as proteínas anti-apoptóticas da família Bcl-2 protegem as células da apoptose, e as proteínas efetoras BAX (do inglês, Bcl-2-associated $x$ 
protein) e BAK (do inglês, Bcl-2 antagonist killer 1) promovem a permeabilização da membrana mitocondrial $(19,20)$. Na via intrínseca, estímulos provocados por estresse ou dano celular induzem a ativação de membros da família BH3-only. Estes, por sua vez, inibem proteínas anti-apoptóticas da família BCL-2-like e induzem a ativação das proteínas BAX e BAK. Uma vez ativadas, BAK e BAX podem formar homo ou hetero oligômeros, resultando na formação de poros na membrana mitocondrial externa e consequentemente na permeabilização desta (MOMP- do inglês, mitochondrial outer membrane permeabilization). Durante a permeabilização da membrana mitocondrial, fatores próapoptóticos são liberados, incluindo o citocromo c. A interação do citocromo c com a molécula APAF1 (do inglês, apoptotic protease activating factor 1) e a pro-caspase-9 formam o complexo denominado apoptossomo, pelo qual a caspase-9 é ativada. A caspase9, então, ativa as caspases efetoras -3 e -7 . Estas, juntamente com a caspase-6, são proteases responsáveis pela clivagem de substratos específicos, resultando nas características apoptóticas. Além disso, as caspases -3 e -7 são capazes de ativar CAD, uma DNAse, por meio do processamento de seu respectivo inibidor ICAD. A endonuclease CAD, uma vez ativada, promove uma fragmentação específica do DNA oligonucleossomal $(16,21-23)$.

Em contrapartida, a via extrínseca (Fig. 2) da apoptose envolve a estimulação dos receptores de morte celular (exemplo: TNF e TRAIL). Fas é um membro da família TNF de receptores, e é também descrito como Apo-1 ou CD95 (24,25). A estimulação do receptor Fas com Fas ligante promove o recrutamento da molécula adaptadora FADD e da pro-caspase-8, resultando na formação do complexo conhecido como DISC (do inglês, death inducing signaling complex). Dentro deste complexo, a caspase-8 é ativada e promove, consequentemente, a ativação das caspases efetoras -3 e -7 , transduzindo o sinal apoptótico (24-27).

Em condições específicas, a via intrínseca pode estabelecer comunicação com a via extrínseca através da caspase- 8 , que promove a clivagem da proteína BID. A proteína BID é um membro da família BH-3 only e sua forma truncada migra para a membrana mitocondrial, promovendo a permeabilização desta e a consequente liberação do citocromo c. A permeabilização mitocondrial resulta na ativação da caspase-9 via apoptossomo e consequentemente na ativação das caspases efetoras, como descrito anteriormente $(23,28)$. 


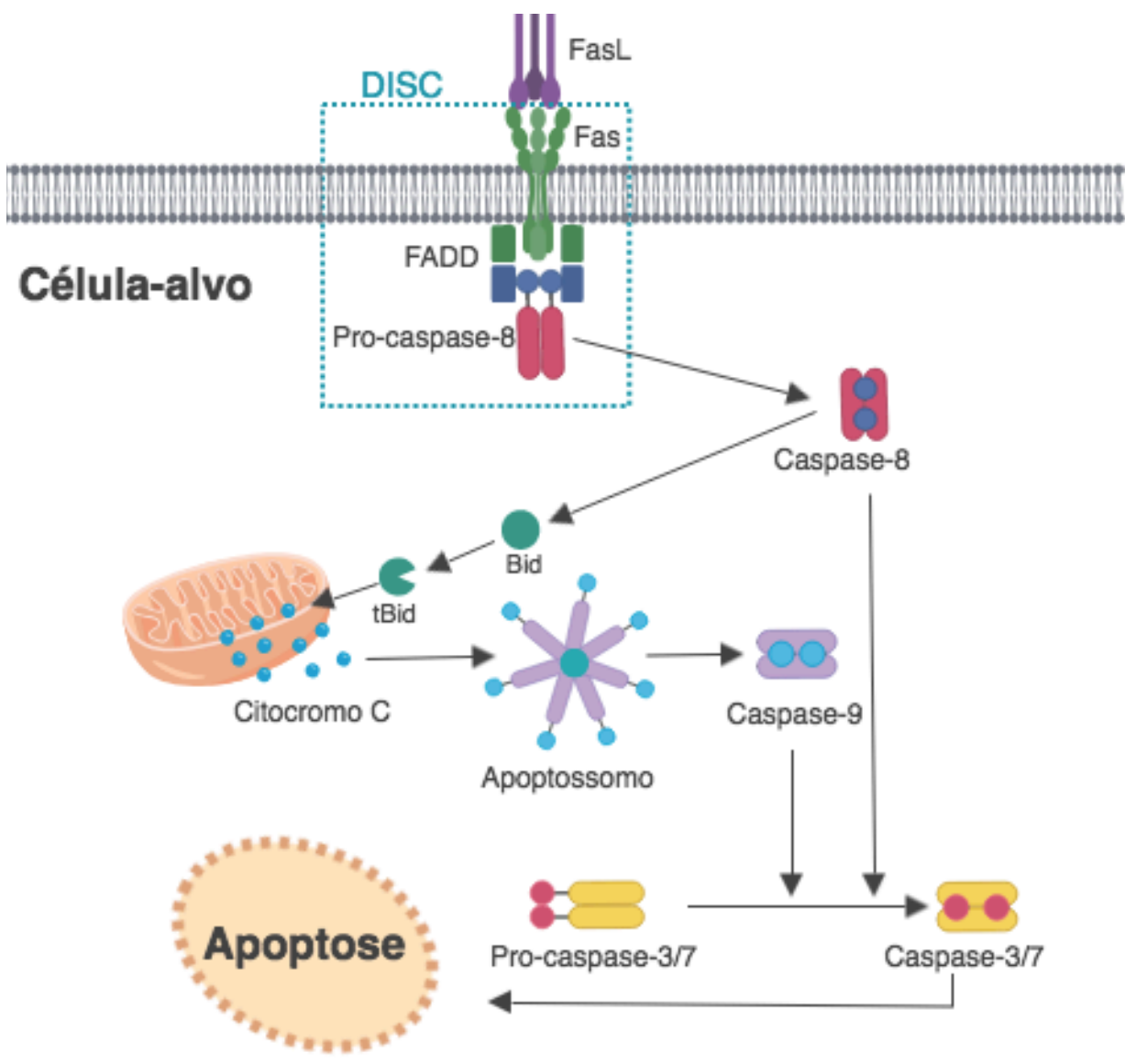

Figura 2. Esquema da via de receptores de morte da apoptose. A estimulação de Fas por FasL promove o recrutamento da proteína adaptadora FADD e a pro-caspase-8, formando o complexo DISC. Dentro desse complexo, a proteína caspase- 8 é ativada, e por sua vez, ativa diretamente as caspases-3/7. Como resultado, a apoptose da célula é desencadeada pela ativação dessas caspases efetoras. Em alguns casos, a caspase- 8 pode clivar a proteína BID, e sua forma truncada se transloca para a membrana externa mitocondrial e promove a liberação de citocromo c. $\mathrm{O}$ citocromo c forma o apoptossomo, juntamente com a proteína adaptadora APAF-1 e pro-caspase-9. Nesse complexo, a caspase-9 é ativada e transmite o sinal às caspases efetoras -3 e -7 , resultando na apoptose. Imagem criada a partir do software Biorender.

A via perforina/granzima (Fig.3) da apoptose é caracterizada pela liberação de grânulos líticos por linfócitos $\mathrm{T}$ citotóxicos após o reconhecimento de células-alvo. Perforina, uma proteína formadora de poros, e granzima, uma serino-protease, são predominantes no conteúdo dos grânulos líticos. Após a liberação do conteúdo granular, monômeros de perforina se oligomerizam na superfície da célula-alvo, formando um poro transmembranar. A formação desse poro na superfície celular resulta na lise osmótica, permitindo a entrada de granzimas no citoplasma da célula-alvo $(29,30)$. Além disso, também foi descrito que granzimas conseguem atingir a porção intracelular por meio da ligação ao receptor de manose 6-fosfato, seguida de endocitose (27). Uma vez no citoplasma, a granzima transduz o sinal apopótico ao promover a ativação de caspases, iniciadoras (caspase-8 e -10), ou efetoras diretamente (caspases -3), e da nuclease CAD, 
por meio de clivagem de seu inibidor ICAD. Estudos também demonstraram que granzimas podem amplificar o sinal apoptótico através da clivagem de BID. Como consequência dessa clivagem, ocorre a permeabilização mitocondrial, resultando na liberação de citocromo c e formação do apoptossomo. Nesse complexo, a caspase-9 é ativada e pode ativar a caspase-3 efetora, resultando na apoptose celular $(27,31,32)$.

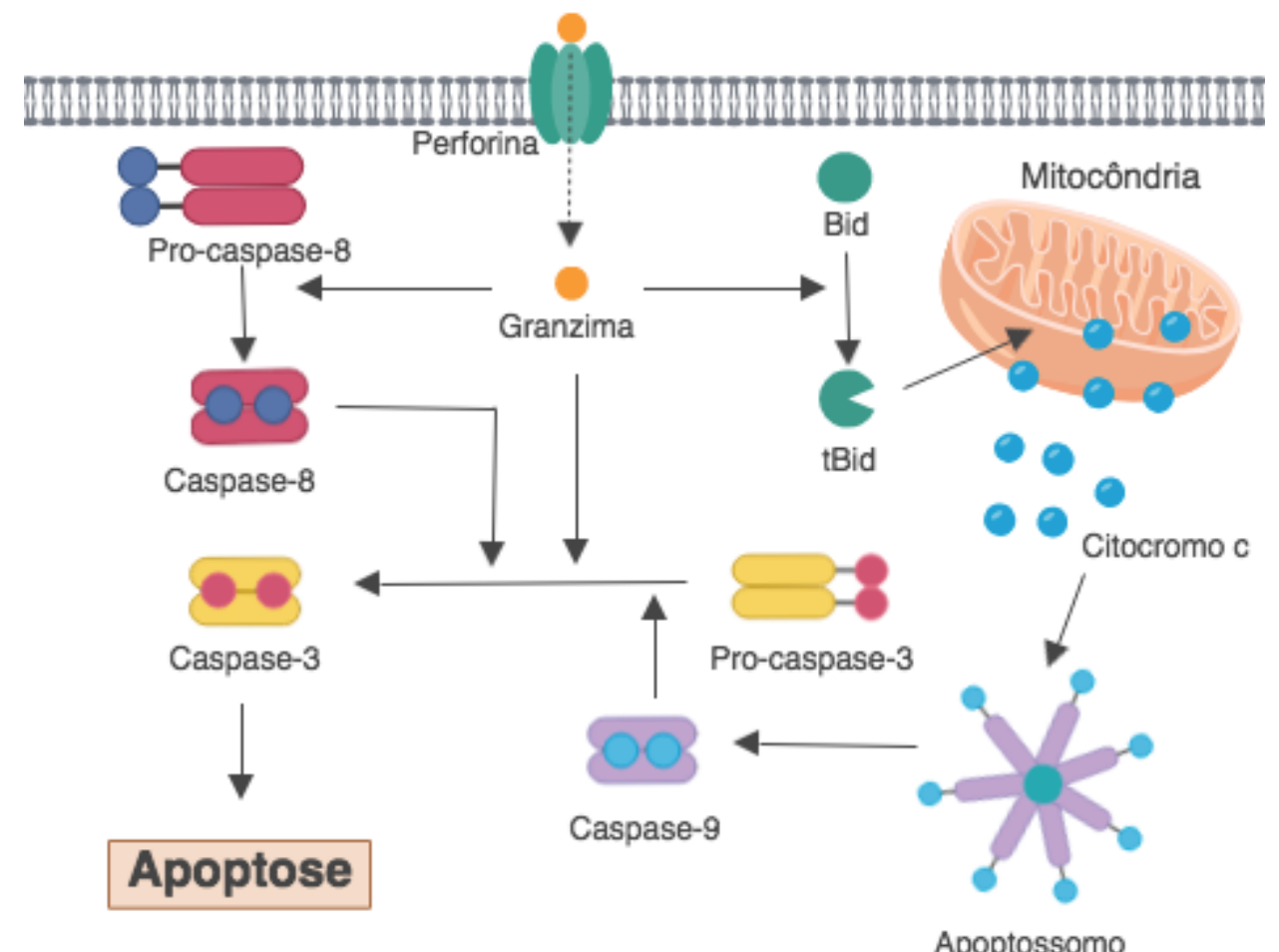

Figura 3. Esquema da via perforina/granzima da apoptose. A translocação da perforina e formação de um poro transmembranar promove a entrada da granzima no citosol da célula-alvo. A granzima, por sua vez, pode clivar a proteína Bid e a proteína Bid truncada (tBid) transloca para a membrana mitocondrial, promovendo a liberação de citocromo $\mathrm{c}$. O citocromo $\mathrm{c}$ atua no complexo apoptossomo, ativando a caspase- 9 , que consequentemente ativa a caspase-3 efetora. A granzima pode ainda ativar a caspase- 8 iniciadora, que ativa a caspase- 3 efetora. Além disso, a granzima pode ativar diretamente a caspase-3 efetora, induzindo a apoptose da célula-alvo. Imagem criada a partir do software Biorender.

\subsection{O papel da caspase-8 na apoptose}

A apoptose é estritamente controlada por caspases iniciadoras e efetoras. As caspases efetoras são diméricas e sua ativação ocorre por meio de clivagem. As caspases iniciadoras, por outro lado, se encontram em forma monomérica e sua ativação dependem da formação de complexos multiméricos em formas dimerizadas (33). A caspase iniciadora, caspase-8, é 
uma cisteína protease, recrutada para o complexo DISC através da interação do seu domínio DED (do inglês, death-effector domain) com um domínio similar na proteína adaptadora. Em células do tipo I, a caspase-8 ativada promove a clivagem e ativação das caspases efetoras -3 e -7. Em células do tipo II, a atividade das caspases é bloqueada por XIAP ( $X$-linked IAP). Portanto, nesses casos, a caspase- 8 ativada promove a clivagem da proteína BID. A forma truncada de BID provoca a permeabilização da membrana externa mitocondrial e a liberação de fatores apoptóticos como SMAC. Em consequência, SMAC inibe a atividade de XIAP, resultando na ativação das caspases efetoras -3 e -7 (28,34)

Em relação a ativação de caspase-8, estudos têm demonstrado que a clivagem em sua subunidade catalítica é necessária. Foi também verificado que, apesar da dimerização gerar atividade para a caspase- 8 , a clivagem desta na unidade catalítica gera estabilidade à sua forma ativa. Assim, para que a caspase-8 induza sinalização apoptótica adequada, esta precisa ser, além de dimerizada, clivada. (35).

A deficiência na caspase- 8 também está associada à perda de homeostase, gerando diversas doenças. Por exemplo, uma alteração genética em caspase- 8 provoca uma imunodeficiência primária denominada CEDS (do inglês, caspase- 8 deficiency state). Essa imunodeficiência é caracterizada pelo acúmulo linfocitário, autoimunidade e apoptose linfocitária deficiente. Essas características são também evidenciadas na imunodeficiência denominada ALPS (do inglês, autoimmune lymphoproliferative syndrome), gerada por mutações que resultam no comprometimento da apoptose $(36,37)$.

A adequada expressão e ativação da caspase-8 é fundamental para a indução da apoptose na célula-alvo. Assim, uma deficiente expressão ou ativação da caspase-8 compromete a sinalização apoptótica na via intrínseca, e também a comunicação com a via extrínseca por meio de clivagem de BID (34). Portanto, a caspase- 8 tem também papel importante na eliminação de células-alvo, uma vez que os linfócitos $\mathrm{T} C D 8^{+}$induzirão a apoptose de células infectadas ou tumorais através de seus mecanismos efetores (27). Nesse sentido, a deficiência da caspase-8 pode comprometer a eficiência dessa eliminação por linfócitos $\mathrm{T} \mathrm{CD}^{+}$. 


\subsection{Linfócitos $\mathrm{T} \mathrm{CDS}^{+}$}

Os linfócitos $\mathrm{T} \mathrm{CD}^{+}$ou linfócitos $\mathrm{T}$ citotóxicos (CTL) desempenham um papel essencial no sistema imune, uma vez que são capazes de reconhecer e eliminar células infectadas ou tumorais $(29,38-40)$. Porém, para que células T CD8 ${ }^{+}$desencadeiem uma resposta efetora e específica contra uma célula-alvo, elas precisam ser previamente ativadas $(41,42)$.

A geração de células $\mathrm{T}$ efetoras e de memória depende de uma prévia apresentação antigênica por uma célula apresentadora de antígeno (do inglês, APC- antigen-presenting cell) (38), o que ocorre nos órgãos linfóides secundários (linfonodos e baço). Após o processo de maturação, que resulta na expressão de receptores antígeno- específicos (do inglês, TCR-T cell receptor) originada por recombinação gênica, e também de moléculas co-receptoras (CD4 ou CD8), as células maduras não ativadas (T naïve) migram para os órgãos linfoides secundários (42). Para que ocorra essa ativação de linfócitos $\mathrm{T}$, estes precisam reconhecer antígenos apresentados por células apresentadoras de antígenos profissionais, que incluem células dendríticas, macrófagos e linfócitos B (43).

O peptídeo específico apresentado aos linfócitos T pelas APCs se liga de forma nãocovalente à moléculas do complexo maior de histocompatibilidade (do inglês, $M H C$ - major histocompatibility complex) de classe I ou classe II (44). No caso de linfócitos T CD $8^{+}$, o coreceptor CD8 interage com o MHC classe I, estabilizando a interação entre o linfócito e a APC. Já no caso de linfócitos T CD4 ${ }^{+}$, o co-receptor CD4 interage com o MHC de classe II. Além da interação do receptor TCR e do co-receptor CD8, moléculas co-estimuladoras e de adesão também participam da interação entre APC e o linfócito T, permitindo a transmissão de sinais. Além da interação entre APC e linfócito, a produção de citocinas pela célula apresentadora de antígeno também tem papel importante na ativação de linfócitos $\mathrm{T}$, na expansão linfocitária e no desenvolvimento de funções efetoras (45-47).

A descoberta da molécula co-estimuladora CD28 forneceu evidências de que esta sinalização representa um segundo sinal para uma completa ativação dos linfócitos $\mathrm{T}$. Assim, os receptores co-estimuladores poderiam transduzir sinais para modular positivamente a sinalização do TCR $(45,48,49)$. Além disso, foram identificados os ligantes de CD28, o B7-1 e o B7-2 em células apresentadoras de antígeno imaturas (50). Ambos os ligantes também podem interagir com o receptor co-inibidor CTLA-4 (do inglês, cytotoxic T lymphocyte antigen 4), que é induzido após a ativação do linfócito $\mathrm{T}$ a fim de suprimir a 
ativação celular. Portanto, as respostas induzidas pela célula T estão sob controle de um complexo sistema de regulação, que pode modular positivamente ou negativamente a sinalização do TCR. (51-54)

Além das moléculas co-estimuladoras, as moléculas de adesão também desempenham um papel fundamental para garantir a interação entre APC e linfócito T. Num modelo de sinapse imunológica, a interação MHC - TCR estaria centralmente localizada, além de envolta e sustentada por moléculas de adesão LFA-1-ICAM-1(46). A expressão de LFA-1 parece aumentar após a estimulação de linfócitos $\mathrm{T}$, e apresenta elevada afinidade por ICAM-1. Nesse sentido, a molécula de adesão LFA-1 parece envolvida na manutenção e força da interação entre o linfócito T e a APC, permitindo completa ativação das células T (54-56).

A presença de citocinas tem sido representada como um outro sinal fundamental na ativação e indução de respostas dos linfócitos $\mathrm{T} \mathrm{CD}^{+}$. Foi demonstrado em experimentos in vitro, que a adição de IL-12 e IFN $\alpha / \beta$ representa um sinal na indução das atividades de linfócitos $\mathrm{T} \mathrm{CD} 8^{+}$. Estudos in vivo utilizando células apresentadoras de antígeno artificiais confirmaram que IL-12 e IFN $\alpha / \beta$, juntamente com o antígeno específico e sinais de coestimulação, interferem positivamente na expansão clonal de células $\mathrm{T} \mathrm{CD}^{+}$e no desenvolvimento de funções efetoras como atividade citolítica e produção de $\operatorname{IFN} \gamma(57,58)$. Além disso, também foi demonstrado que IL-2 é um potente fator de crescimento para as células $\mathrm{T}$ e que estes são essenciais na expansão e sobrevivência de linfócitos T CD8 ${ }^{+}$. Assim, uma completa ativação de linfócitos depende, não somente da interação TCR-MHC, como também da co-estimulação, das moléculas de adesão que garantem uma eficiente interação célula T-APC e de citocinas que funcionam como um sinal adicional essencial (59).

Uma vez ativados, os linfócitos $\mathrm{T} \mathrm{CD} 8^{+}$efetores migram dos órgãos linfóides para a periferia, onde podem reconhecer e eliminar diretamente células-alvo infectadas ou tumorais (41). Todas as células nucleadas do organismo apresentam a molécula de MHC classe I (60). Dessa forma, quando infectadas, apresentam peptídeos derivados da degradação das proteínas dos patógenos intracelulares aos linfócitos $\mathrm{T} \mathrm{CD}^{+}$via $\mathrm{MHC}$ de classe I. As células tumorais, no entanto, podem sofrer um acúmulo de mutações. Como consequência, produzem proteínas mutadas, das quais peptídeos cancerígenos se originam e são apresentados aos linfócitos $\mathrm{T}$ $\mathrm{CD}^{+}$via fenda do MHC de classe I. Os linfócitos $\mathrm{T} \mathrm{CD} 8^{+}$são capazes de reconhecer esses peptídeos apresentados via moléculas de MHC de classe I e promovem a eliminação das células-alvo por mecanismos efetores específicos $(38,61)$. 


\subsection{Mecanismos efetores de linfócitos $T$ citotóxicos}

Após o reconhecimento das células-alvo, os linfócitos $\mathrm{T} \mathrm{CD}^{+}$desencadeiam mecanismos efetores específicos com o objetivo de eliminar a célula infectada ou tumoral, sem danificar o tecido saudável. Para isso, os linfócitos $\mathrm{T} \mathrm{CD}^{+}$apresentam dois mecanismos de ação principais bem descritos (Fig.4) (27).

Um desses mecanismos envolve a liberação de grânulos líticos, os quais são compostos principalmente por perforina e granzimas. A síntese dessas moléculas ocorre durante a maturação e ativação linfocitária e, uma vez sintetizadas, são armazenadas em grânulos líticos no citosol das células $\mathrm{T} \mathrm{CD}^{+}$. Após o reconhecimento de uma célula-alvo pelo linfócito $\mathrm{T} \mathrm{CD}^{+}$, a liberação do conteúdo dos grânulos líticos ocorre de forma direcionada. Posteriormente a essa liberação, a perforina e as granzimas atuam de forma específica a fim de induzir a apoptose da célula-alvo, infectada ou malignizada. A perforina sofre oligomerização, promovendo a formação de um poro transmembranar, o que permite a entrada de granzimas na célula-alvo. Estas, por sua vez, podem promover a ativação da caspase-8, iniciadora, ou das caspases efetoras -3 e -7. A granzima pode ainda clivar a molécula BID, que se transloca para a membrana externa mitocondrial, promovendo sua permeabilização. Como consequência, há a liberação do citocromo c, resultando na formação do apoptossomo, e ativação da caspase-9, conforme mencionado anteriormente $(27,29,32)$.

Enquanto que o outro mecanismo efetor dos linfócitos $\mathrm{T} C D 8^{+}$ocorre por estimulação do receptor de morte Fas (CD95) na célula-alvo, com seu respectivo ligante na células T, FasL (CD95L). A interação entre esse receptor com seu ligante promove a ativação de uma sinalização apoptótica específica na célula-alvo. Esse sinal apoptótico gerado a partir do engajamento Fas-FasL promove a formação do complexo DISC, sendo composto pela molécula adaptadora FADD e da pro-caspase-8. A partir da formação desse complexo, a ativação da caspase-8 leva ao comprometimento das caspases efetoras -3 e -7 , resultando na eliminação da célula-alvo por apoptose. $(27,62)$. 


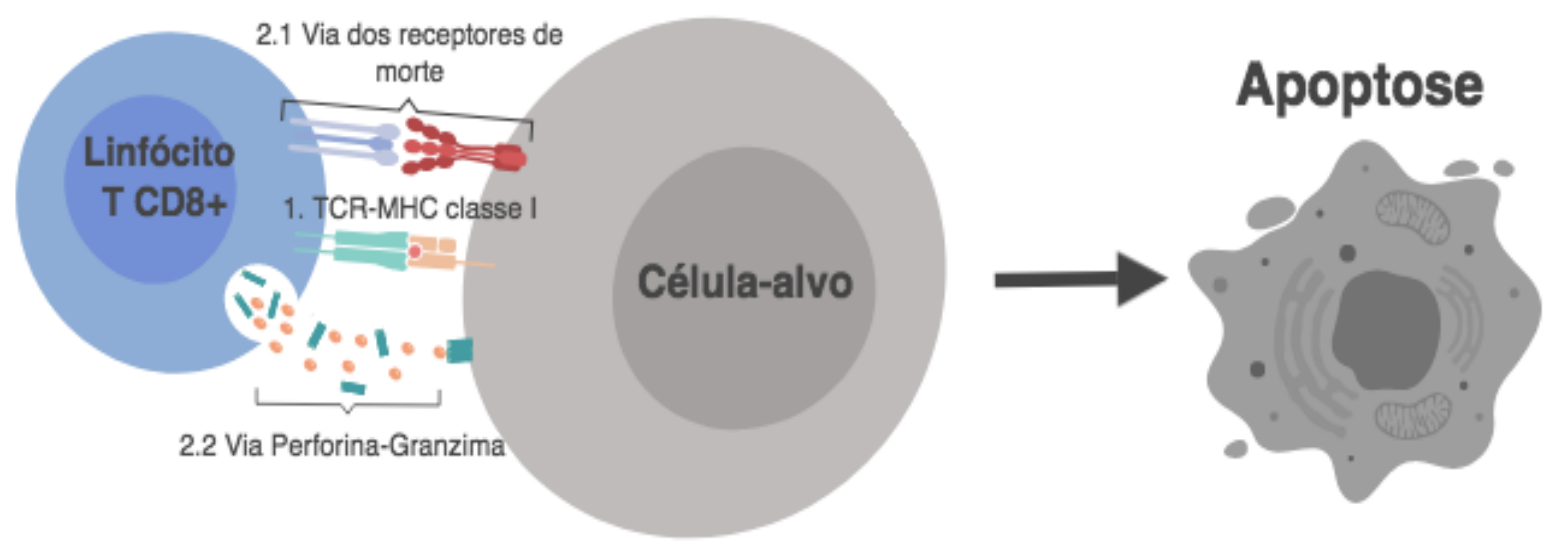

Figura 4. Mecanismos efetores dos linfócitos $\mathbf{T ~ C D 8}^{+}$. Após o reconhecimento de células-alvo via MHC de classe I (1), os linfócitos $\mathrm{T} C \mathrm{CD} 8^{+}$ou citotóxicos podem desencadear a apoptose da célulaalvo pela via dos receptores de morte (2.1)- interação Fas-FasL- ou pela via perforina-granzima com a liberação de grânulos. Imagem criada pelo software Biorender.

\subsection{Manutenção da resposta gerada por linfócitos $\mathrm{TCD8}^{+}$}

Durante uma resposta imune, há uma expansão clonal dos linfócitos específicos aos antígenos apresentados, no intuito de aumentar a eficiência da resposta contra uma célulaalvo. Porém, após a eliminação da célula-alvo, é necessário uma contração linfocitária a fim de retornar à homeostase. Assim, o número de linfócitos antígeno-específicos reduz consideravelmente, restando apenas linfócitos $\mathrm{T} C D 8^{+}$de memória. Há dois principais mecanismos envolvidos na contração linfocitária: ACAD (do inglês, Activated T Cell Autonomous Death) e AICD (do inglês, Activated-Induced Cell Death) (63).

A estimulação do TCR em células ativadas e expandidas em conjunto com a ausência de co-estimulação promove a indução do mecanismo de AICD. Esse mecanismo é induzido pela estimulação dos receptores de morte Fas por FasL e resulta na sinalização da via extrínseca da apoptose $(63,64)$.

O mecanismo de ACAD, por outro lado, é causado pela ausência de sinais de sobrevivência ao linfócito $\mathrm{T}$. $\mathrm{O}$ processo de ACAD é mediado principalmente pelo membro da família Bcl-2, a proteína BIM, que se liga a $\mathrm{Bcl}-2$ ou $\mathrm{Bcl}-\mathrm{X}_{\mathrm{L}}$, resultando na ativação das proteínas BAX e BAK e, consequentemente, na liberação do citocromo c pela mitocôndria. O mecanismo de ACAD ocorre principalmente em estimulações agudas, enquanto que AICD ocorre principalmente em estimulações crônicas $(63,64)$. 
A apoptose está, portanto, envolvida não apenas nos mecanismos efetores dos linfócitos $\mathrm{T}$, como também na contração linfocitária após a eliminação do antígeno. Nesse contexto, o funcionamento adequado da maquinaria apoptótica e uma eficiente sinalização são fundamentais na indução das respostas efetoras das células $\mathrm{T}$, na homeostase linfocitária e no controle de autoimunidade (65).

\subsection{Caspase-8 e a evasão imune no câncer}

Devido a relevância da caspase-8 na sinalização apoptótica, esta está diretamente associada à eficiência que células $\mathrm{T}$ citotóxicas eliminam células-alvo infectadas e tumorais. Nesse sentido, células tumorais podem apresentar mutações no gene da caspase8, representando um possível mecanismo de evasão à eliminação por linfócitos $\mathrm{T}$ citotóxicos. Um estudo recente demonstrou que câncer de cabeça e pescoço, câncer coloretal e uterino, além de carcinoma escamoso pulmonar apresentam mutação no gene da caspase-8 (CASP8). Esse estudo sugere, portanto, que a disfunção ou deficiente expressão de caspase- 8 pode representar um mecanismo de evasão imune pela célula tumoral, com consequências para a formação tumoral, progressão e resistência ao tratamento (66).

Outros estudos também demonstraram que o polimorfismo no gene da caspase-8 está associado com maiores riscos de carcinoma epidermóide esofágico $(67,68)$ e que em amostras de carcinoma de pulmão de célula-pequena, há metilação das ilhas $\mathrm{CpG}$ do promotor de caspase-8 (69). Em análise de amostras de câncer coloretal humano, cerca de $30 \%$ das hipermutadas apresentam alterações de sequência no gene da caspase-8 (70). Assim, alterações na expressão de caspase-8 estão diretamente relacionadas com maior incidência de tipos de câncer específicos.

A inativação ou a deficiente expressão de caspase- 8 pode representar uma evasão à apoptose pela célula tumoral, o que interfere, consequentemente, na resistência a atuais tratamentos contra o câncer (71). Além disso, também foi demonstrado que a caspase- 8 pode atuar de forma não-proteolítica na sinalização inflamatória induzida por TRAIL. Portanto, sugere-se que células tumorais podem promover mutações específicas apenas na região proteolítica da caspase- 8 , induzindo um contexto inflamatório e evadindo à apoptose (72). Nesse contexto, é fundamental entender o papel da caspase-8, especialmente na eliminação de células tumorais. 


\subsection{RMA e RMA-S como modelos de células tumorais}

Nesse projeto, as linhagens celulares RMA e RMA-S foram utilizadas como modelos de células tumorais para experimentos in vitro. As células RMA e RMA-S são sublinhagens de linfoma T RBL-5, induzido por vírus Rauscher. As células RMA foram induzidas a mutagenização através de tratamento com etanometanosulfonado, $200 \mu \mathrm{g} / \mathrm{ml}$ por 24 horas. Após esse tratamento, as células foram recuperadas por 1 semana e tratadas com aloantisoro e complemento de coelho por 1-4 horas. Este tratamento foi repetido quatro vezes. Células que foram resistentes a esse tratamento devido a níveis reduzidos de MHC de classe I na superfície foram selecionadas. As células selecionadas foram avaliadas quanto a eliminação por linfócitos T citotóxicos no ensaio de liberação de crômio. Foi observado que essas células variantes (RMA-S) tem eliminação reduzida, uma vez que apresentam redução de MHC de classe I na sua superfície celular (73).

Uma melhor caracterização dessas células variantes demonstrou que a redução nos níveis de MHC de classe I na superfície das células RMA-S se deve a deficiência na montagem da molécula de MHC com peptídeos antigênicos. Essa deficiência foi gerada por uma mutação pontual no gene da TAP-2, que resulta em um stop códon e consequentemente em uma proteína incompleta e deficiente (74).

A proteína TAP-2 tem papel fundamental na apresentação antigênica da molécula de MHC de classe I. Nesta via de apresentação, proteínas do citoplasma são processadas pelo proteassoma. Os peptídeos gerados desse processamento são translocados para o lúmen do retículo endoplasmático através da proteína TAP. As moléculas de MHC de classe I, composta pela cadeia pesada e sua associada $\beta 2$-microglobulina, é formada no lúmen do retículo endoplasmático com o auxílio de chaperonas. A molécula de MHC de classe I se associa, então, com TAP e tapasina facilita o carregamento do peptídeo na fenda do MHC de classe I. A ligação do peptídeo promove a dissociação da TAP e o transporte das moléculas estáveis de MHC de classe I carregadas com peptídeos antigênicos através da via secretória para a membrana plasmática $(60,75)$.

Assim, mutações no gene de TAP2 nas células RMA-S resultam em uma proteína aberrante, de menor tamanho e que, por esse motivo, não formaria um heterodímero funcional com a proteína TAP1. Como consequência, há uma falha no carregamento de peptídeos a moléculas de MHC de classe I no retículo endoplasmático. Fenotipicamente, essa deficiência resulta em menor expressão de MHC de classe I na superfície das células RMA-S (76). 
Devido à expressão reduzida de MHC de classe I na superfície celular e a sua reduzida eliminação por linfócitos T citotóxicos, as células RMA-S foram utilizadas como controles neste projeto. A utilização dessas células como controle na técnica de citotoxicidade in vitro desenvolvida permite a análise da especificidade ao MHC de classe I da técnica estabelecida. 


\section{CONCLUSÃO}

- Os ensaios de citotoxicidade in vitro utilizando células RMA e RMA-S como alvos e blastos OTI estimulados permitiu a avaliação da eliminação antígeno-específica.

- Na razão efetor: alvo (E:A) de 1:8, a discriminação entre células fenotipicamente distintas é mais eficiente. Nessa condição, a eliminação de células RMA-S foi significantemente menor, em comparação com as células RMA, para todas as concentrações de peptídeo pulsado a partir de 10pM.

- A utilização das células caspase-8-suficientes e caspase-8-deficientes no ensaio de citotoxicidade in vitro, na razão E:A de 1:8, sugere que essas células deficientes são mais resistentes à eliminação por linfócitos T CD8+.

Portanto, nossos resultados vão de acordo com a linha de pensamento de que a deficiência em caspase- 8 pode representar um mecanismo de evasão imune. 


\section{REFERÊNCIAS}

1. Duprez L, Wirawan E, Berghe T Vanden, Vandenabeele P. Major cell death pathways at a glance. Microbes Infect. 2009;11(13):1050-62. [10.1016/j.micinf.2009.08.013]

2. Galluzzi L, Vitale I, Aaronson SA, Abrams JM, Adam D, Agostinis P, et al. Molecular mechanisms of cell death: Recommendations of the Nomenclature Committee on Cell Death 2018. Cell Death Differ. 2018;25(3):486-541. [10.1038/s41418-017-0012-4]

3. Galluzzi L, Maiuri MC, Vitale I, Zischka H, Castedo M, Zitvogel L, et al. Cell death modalities: Classification and pathophysiological implications. Cell Death Differ. 2007;14(7):1237-43. [10.1038/sj.cdd.4402148]

4. Kroemer $G$, Jäättelä M. Lysosomes and autophagy in cell death control. Nat Rev Cancer. 2005;5(11):886-97. [10.1038/nrc1738]

5. Berghe $\mathrm{T}$ Vanden, Linkermann A, Jouan-Lanhouet S, Walczak H, Vandenabeele P. Regulated necrosis: The expanding network of non-apoptotic cell death pathways. Nat Rev Mol Cell Biol. 2014;15(2):135-47. [10.1038/nrm3737]

6. Weinlich R, Oberst A, Beere HM, Green DR. Necroptosis in development, inflammation and disease. Nat Rev Mol Cell Biol. 2017;18(2):127-36. [10.1038/nrm.2016.149]

7. Sun L, Wang H, Wang Z, He S, Chen S, Liao D, et al. Mixed Lineage Kinase Domainlike Protein Mediates Necrosis Signaling Downstream of RIP3 Kinase. Cell. 2012;148(1-2):213-27. [10.1016/j.cell.2011.11.031]

8. Wang H, Sun L, Su L, Rizo J, Liu L, Wang L-F, et al. Mixed Lineage Kinase Domainlike Protein MLKL Causes Necrotic Membrane Disruption upon Phosphorylation by RIP3. Mol Cell. 2014;54(1):133-46. [10.1016/j.molcel.2014.03.003]

9. Kaiser WJ, Upton JW, Long AB, Livingston-Rosanoff D, Daley-Bauer LP, Hakem R, et al. RIP3 mediates the embryonic lethality of caspase-8-deficient mice. Nature. 2011;471(7338):368-72. [10.1038/nature09857]

10. Christofferson DE, Li Y, Hitomi J, Zhou W, Upperman C, Zhu H, et al. A novel role for RIP1 kinase in mediating TNFa production. Cell Death Dis. 2012;3(6):1-10. [10.1038/cddis.2012.64]

11. Dondelinger Y, Aguileta MA, Goossens V, Dubuisson C, Grootjans S, Dejardin E, et al. RIPK3 contributes to TNFR1-mediated RIPK1 kinase-dependent apoptosis in conditions of cIAP1/2 depletion or TAK1 kinase inhibition. Cell Death Differ. 2013;20(10):1381-92. [10.1038/cdd.2013.94]

12. Donepudi M, Sweeney A Mac, Briand C, Grütter MG. Insights into the regulatory mechanism for caspase-8 activation. Mol Cell. 2003;11(2):543-9. [10.1016/S10972765(03)00059-5]

13. Zhou W, Yuan J. Necroptosis in health and diseases. Semin Cell Dev Biol. 2014;35:14-23. [10.1016/j.semcdb.2014.07.013]

14. Fuchs Y, Steller H. Programmed cell death in animal development and disease. Cell. 2011;147(4):742-58. [10.1016/j.cell.2011.10.033]

15. KERR JFR, Wyllie AH, Currie AAR. Apoptosis: a Basic Biological Phenomenon With Wide- Ranging Implications in Tissue Kinetics. J Intern Med. 1972;258(6):479-517. [10.1111/j.1365-2796.2005.01570.x]

16. Taylor RC, Cullen SP, Martin SJ. Apoptosis: controlled demolition at the cellular level. Nat Rev Mol Cell Biol. 2008;9(3):231-41. [10.1038/nrm2312]

17. Blander JM. A long-awaited merger of the pathways mediating host defence and programmed cell death. Nat Rev Immunol [Internet]. 2014;14(9):601-18. [10.1038/nri3720] 
18. Elmore S. Apoptosis: a review of programmed cell death. Toxicol Pathol. 2007 ;35(4):495-516. [10.1080/01926230701320337]

19. Czabotar PE, Lessene G, Strasser A, Adams JM. Control of apoptosis by the BCL-2 protein family: implications for physiology and therapy. Nat Rev Mol Cell Biol. 2014; 15(1):49-63. [10.1038/nrm3722]

20. Zhong Y, Weininger M, Pirbhai M, Dong F, Zhong G. Inhibition of staurosporineinduced activation of the proapoptotic multidomain Bcl-2 proteins Bax and Bak by three invasive chlamydial species. J Infect. 2006;53(6):40814.[10.1016/j.jinf.2005.12.028]

21. Ichim G, Tait SWG. A fate worse than death: apoptosis as an oncogenic process. Nat Rev Cancer. 2016;16(8):539-48. [10.1038/nrc.2016.58]

22. Saelens X, Festjens N, Vande Walle L, van Gurp M, van Loo G, Vandenabeele P. Toxic proteins released from mitochondria in cell death. Oncogene. 2004;23(16):286174. [10.1038/sj.onc.1207523]

23. Galluzzi L, Blomgren K, Kroemer G. Mitochondrial membrane permeabilization in neuronal injury. Nat Rev Neurosci. 2009;10(7):481-94. [10.1038/nrn2665]

24. Peter ME, Krammer PH. The CD95(APO-1/Fas) DISC and beyond. Cell Death Differ. 2003;10(1):26-35. [10.1038/sj.cdd.4401186]

25. Schütze S, Tchikov V, Schneider-Brachert W. Regulation of TNFR1 and CD95 signalling by receptor compartmentalization. Nat Rev Mol Cell Biol. 2008; 9(8):65562. [10.1038/nrm2430]

26. Strasser A, O'Connor L, Dixit VM. Apoptosis Signaling. Annu Rev Biochem. 2000;69(1):217-45. [10.1038/nrm2430]

27. van den Brink MRM, Burakoff SJ. Cytolytic Pathways in Haematopoietic Stem-Cell Transplantation. Nat Rev Immunol. 2002;2(4):273-81. [10.1038/nri775]

28. Schug Z, Gonzalvez F, Houtkooper R, Vaz F, Gottlieb E. BID is cleaved by caspase-8 within a native complex on the mitochondrial membrane. Cell Death Differ. 2010;18(10):538-48. [10.1038/cdd.2010.135]

29. Andersen MH, Schrama D, thor Straten P, Becker JC. Cytotoxic T Cells. Vol. 126, Journal of Investigative Dermatology. 2006. p. 32-41. [10.1038/sj.jid.5700001]

30. Trapani JA, Smyth MJ. Functional significance of the perforin/granzyme cell death pathway. Nat Rev Immunol. 2002;2(10):735-47. [10.1038/nri911]

31. Pardo J, Wallich R, Martin P, Urban C, Rongvaux a, Flavell R a, et al. Granzyme Binduced cell death exerted by ex vivo CTL: discriminating requirements for cell death and some of its signs. Cell Death Differ. 2008;15(3):567-79. [10.1038/sj.cdd.4402289]

32. Trapani JA, Smyth MJ. Functional significance of the perforin/granzyme cell death pathway. Nat Rev Immunol. 2002;2(10):735-47. [10.1038/nri911]

33. Degterev A, Boyce M, Yuan J. A decade of caspases. Oncogene. 2003;22(53):854367. [10.1038/sj.onc.1207107]

34. Kruidering M, Evan G. Caspase-8 in Apoptosis: The Beginning of "The End"? IUBMB Life [Internet]. 2000;50(2):85-90. [10.1080/713803693]

35. Kominami K, Nakabayashi J, Nagai T, Tsujimura Y, Chiba K, Kimura H, et al. The molecular mechanism of apoptosis upon caspase-8 activation: Quantitative experimental validation of a mathematical model. Biochim Biophys Acta - Mol Cell Res. 2012;1823(10):1825-40. [10.1016/j.bbamcr.2012.07.003]

36. Su HC, Lenardo MJ. Genetic Defects of Apoptosis and Primary Immunodeficiency. Immunol Allergy Clin North A. 2008;28(2):329. [10.1016/j.iac.2008.01.002.Genetic]

37. Niemela J, Kuehn HS, Kelly C, Zhang M, Davies J, Melendez J, et al. Caspase-8 Deficiency Presenting as Late-Onset Multi-Organ Lymphocytic Infiltration with Granulomas in two Adult Siblings. J Clin Immunol. 2015;35(4):348-55. 
[10.1007/s10875-015-0150-8]

38. Albert ML, Darnell RB. Paraneoplastic neurological degenerations: keys to tumour immunity. Nat Rev Cancer. 2004; 4(1):36-44. [10.1038/nrc1255]

39. Barry M, Bleackley RC. Cytotoxic T lymphocytes: all roads lead to death. Nat Rev Immunol. 2002;2(6):401-9. [10.1038/nri819]

40. Stinchcombe JC, Griffiths GM. Secretory Mechanisms in Cell-Mediated Cytotoxicity. Annu Rev Cell Dev Biol. 2007;23(1):495-517. [10.1146/annurev.cellbio.23.090506.123521]

41. Pennock ND, White JT, Cross EW, Cheney EE, Tamburini BA, Kedl RM. T cell responses: naive to memory and everything in between. Adv Physiol Educ. American Physiological Society; 2013;37(4):273-83. [10.1152/advan.00066.2013]

42. Germain RN. T-cell development and the CD4-CD8 lineage decision. Nat Rev Immunol. 2002;2(5):309-22. [10.1038/nri798]

43. Kambayashi T, Laufer TM. Atypical MHC class II-expressing antigen-presenting cells: can anything replace a dendritic cell? Nat Rev Immunol [Internet]. Nature Publishing Group; 2014;14(11):719-30. [10.1038/nri3754]

44. Bevan MJ. Helping the CD8+ T-cell response. Nat Rev Immunol. 2004;4(8):595-602. [10.1038/nri1413]

45. Dustin ML. The immunological synapse. Cancer Immunol Res.2014;2(11):1023-33. [10.1158/2326-6066.CIR-14-0161]

46. Freiberg BA, Kupfer H, Maslanik W, Delli J, Kappler J, Zaller DM, et al. Staging and resetting $T$ cell activation in SMACs. Nat Immunol. 2002;3(10):911-7. [10.1038/ni836]

47. Dockree T, Holland CJ, Clement M, Ladell K, McLaren JE, van den Berg HA, et al. CD8+ T-cell specificity is compromised at a defined MHCI/CD8 affinity threshold. Immunol Cell Biol. 2017;95(1):68-76. [10.1038/icb.2016.85]

48. Pufnock JS, Cigal M, Rolczynski LS, Andersen-Nissen E, Wolfl M, McElrath MJ, et al. Priming CD8+ T cells with dendritic cells matured using TLR4 and TLR7/8 ligands together enhances generation of CD8+ T cells retaining CD28. Blood. 2011; 117(24): 6542-6551. [10.1182/blood-2010-11-317966]

49. Bromley SK, Iaboni A, Davis SJ, Whitty A, Green JM, Shaw AS, et al. The immunological synapse and CD28-CD80 interactions. Nat Immunol. 2001;2(12):115966. [10.1038/ni737]

50. Chen L, Flies DB. Molecular mechanisms of $\mathrm{T}$ cell co-stimulation and co-inhibition. Nat Rev Immunol. 2013;13(4):227-42. [10.1038/nri3405]

51. Buchbinder EI, Desai A. CTLA-4 and PD-1 pathways similarities, differences, and implications of their inhibition. Am J Clin Oncol. 2016;39(1):98-106. [10.1097/COC.0000000000000239]

52. Riley JL, June CH. The CD28 family: A T-cell rheostat for therapeutic control of Tcell activation. Blood. 2005;105(1):13-21. [10.1182/blood-2004-04-1596]

53. Boesteanu AC, Katsikis PD. Memory T cells need CD28 costimulation to remember. Semin Immunol. 2009;21(2):69-77. [10.1016/j.smim.2009.02.005]

54. Schneider H, Valk E, da Rocha Dias S, Wei B, Rudd CE. CTLA-4 up-regulation of lymphocyte function-associated antigen 1 adhesion and clustering as an alternate basis for coreceptor function. Proc Natl Acad Sci. 2005;102(36):12861-6. [10.1073/pnas.0505802102]

55. Bachmann MF, McKall-Faienza K, Schmits R, Bouchard D, Beach J, Speiser DE, et al. Distinct Roles for LFA-1 and CD28 during Activation of Naive T Cells: Adhesion versus Costimulation. Immunity. 1997;7(4):549-57. [10.1016/S1074-7613(00)803763] 
56. Li D, Molldrem JJ, Ma Q. LFA-1 regulates CD8+ T cell activation via T cell receptormediated and LFA-1-mediated Erk1/2 signal pathways. $J$ Biol Chem. 2009;284(31):21001-10. [10.1074/jbc.M109.002865]

57. Cuda CM, Pope RM, Perlman H. The inflammatory role of phagocyte apoptotic pathways in rheumatic diseases. Nat Rev Rheumatol. 2016;12(9):543-58. [10.1038/nrrheum.2016.132]

58. Cox MA, Kahan SM, Zajac AJ. Anti-viral CD8 T cells and the cytokines that they love. 2014;435(1):157-69. [10.1016/j.virol.2012.09.012]

59. Cho J-H, Kim H-O, Kim K-S, Yang D-H, Surh CD, Sprent J. Unique Features of Naive CD8+ $\mathrm{T}$ Cell Activation by IL-2. J Immunol. 2013;191(11). [10.4049/jimmunol.1302293]

60. Hewitt EW. The MHC class I antigen presentation pathway: Strategies for viral immune evasion. Immunology. 2003;110(2):163-9. [10.1038/nri2575

61. Maher J, Davies ET. Targeting cytotoxic T lymphocytes for cancer immunotherapy. Br J Cancer [Internet]. 2004;817-21. Available from: http://www.nature.com/doifinder/10.1038/sj.bjc.6602022

62. Waring P, Mullbacher A. Cell death induced by the Fas/Fas ligand pathway and its role in pathology. Immunol Cell Biol. 1999;77(4):312-7. [10.1046/j.14401711.1999.00837.x]

63. Arnold R, Brenner D, Becker M, Frey CR, Krammer PH. How T lymphocytes switch between life and death. Eur J Immunol. 2006;36(7):1654-8. [10.1002/eji.200636197]

64. Krammer PH, Arnold R, Lavrik IN. Life and death in peripheral T cells. Nat Rev Immunol [Internet]. 2007;7(7):532-42.[10.1038/nri2115]

65. Marrack P, Scott-Browne J, MacLeod MKL. Terminating the immune response. Immunol Rev. 2010;236(1):5-10. [10.1111/j.1600-065X.2010.00928.x]

66. Rooney MS, Shukla SA, Wu CJ, Getz G, Hacohen N. Molecular and genetic properties of tumors associated with local immune cytolytic activity. Cell. 2015;160(1-2):48-61. [10.1016/j.cell.2014.12.033]

67. Takikita M, Hu N, Shou J, Wang Q-H, Giffen C, Taylor PR, et al. Biomarkers of apoptosis and survival in esophageal squamous cell carcinoma. BMC Cancer. 2009;9(1):310. [10.1186/1471-2407-9-310]

68. Tang YI, Liu Y, Zhao W, Yu T, Yu H. Caspase-8 polymorphisms and risk of oral squamous cell carcinoma. Exp Ther Med. 2015;10(6):2267-76. [10.3892/etm.2015.2832]

69. Hopkins-Donaldson S, Ziegler A, Kurtz S, Bigosch C, Kandioler D, Ludwig C, et al. Silencing of death receptor and caspase-8 expression in small cell lung carcinoma cell lines and tumors by DNA methylation. Cell Death Differ. 2003;10(3):356-64. [10.1038/sj.cdd.4401157]

70. Muzny DM, Bainbridge MN, Chang K, Dinh HH, Drummond JA, Fowler G, et al. Comprehensive molecular characterization of human colon and rectal cancer. Nature. 2012;487(7407):330-7. [10.1038/nature11252]

71. He GW, Günther C, Thonn V, Yu YQ, Martini E, Buchen B, et al. Regression of apoptosis-resistant colorectal tumors by induction of necroptosis in mice. 2017;4-11. [10.1084/jem.20160442]

72. Henry CM, Martin SJ. Caspase-8 Acts in a Non-enzymatic Role as a Scaffold for Assembly of a Pro-inflammatory FADDosome Complex upon TRAIL Stimulation. Mol Cell. 2017;65(4):715-729.e5. [10.1016/j.molcel.2017.01.022]

73. Kärre K, Ljunggren HG, Piontek G, Kiessling R. Selective rejection of H-2-deficient lymphoma variants suggests alternative immune defence strategy. Nature. 1986;319(6055):675-8. [10.1038/319675a0] 
74. Yang $\mathrm{Y}$, Fruh $\mathrm{K}$, Chambers J, Waters JB, Wu L, Spies $\mathrm{T}$, et al. Major histocompatibility complex (MHC)-encoded HAM2 is necessary for antigenic peptide loading onto class I MHC molecules. J Biol Chem. 1992;267(17):11669-72.

75. Villadangos JA, Schnorrer P. Intrinsic and cooperative antigen-presenting functions of dendritic-cell subsets in vivo. Nat Rev Immunol. 2007;7(7):543-55. [10.1038/nri2103]

76. Ossevoort MA, Sijts AJAM, van Veen KJH, Momburg F, Hämmerling GJ, Seelig A, et al. Differential effect of transporter Tap 2 gene introduction into RMA-S cells on viral antigen processing. Eur J Immunol. 1993;23(12):3082-8. [10.1002/eji.1830231206]

77. Clarke SRmK, Barnden M, Kurts C, Carbone FR, Miller JF, Heath WR. Characterization of the ovalbumin-specific TCR transgenic line OT-I: MHC elements for positive and negative selection. Immunol Cell Biol. 2000;78(2):110-7. [10.1046/j.1440-1711.2000.00889.x]

78. Wands JR, Podolsky DK, Isselbacher KJ. Mechanism of human lymphocyte stimulation by concanavalin A: role of valence and surface binding sites. Proc Natl Acad Sci U S A. 1976;73(6):2118-22.

79. Bemer $\mathrm{V}$, Truffa-Bachi $\mathrm{P}$. T cell activation by concanavalin $\mathrm{A}$ in the presence of cyclosporin A: immunosuppressor withdrawal induces NFATp translocation and interleukin-2 gene transcription. Eur J Immunol. 1996;26(7):1481-8. [10.1002/eji.1830260712]

80. Au-Yeung BB, Smith GA, Mueller JL, Heyn CS, Jaszczak RG, Weiss A, et al. IL-2 Modulates the TCR Signaling Threshold for CD8 but Not CD4 T Cell Proliferation on a Single-Cell Level. J Immunol. 2017;198(6):2445-56. [10.4049/jimmunol.1601453]

81. Clemente T, Dominguez MR, Vieira NJ, Rodrigues MM, Amarante-Mendes GP. In vivo assessment of specific cytotoxic T lymphocyte killing. Methods. 2013;61(2):1059. [10.1016/j.ymeth.2013.02.007]

82. De Silva A, Boesteanu A, Song R, Nagy N, Harhaj E, Harding C, et al. Thermolabile $\mathrm{H}-2 \mathrm{~Kb}$ molecules expressed by transporter associated with antigen processing-deficient RMA-S cells are occupied by low-affinity peptides. J Immunol. 1999;163(8):4413-20.

83. De Bruijn MLH, Schumacher TNM, Nieland JD, Ploegh HL, Martin Kast W, Melief CJM. Peptide loading of empty major histocompatibility complex molecules on RMA$\mathrm{S}$ cells allows the induction of primary cytotoxic $\mathrm{T}$ lymphocyte responses. Eur $\mathrm{J}$ Immunol. 1991;21(12):2963-70. [10.1002/eji.1830211210]

84. Evans K, Albanetti T, Venkat R, Schoner R, Savery J, Miro-Quesada G, et al. Assurance of monoclonality in one round of cloning through cell sorting for single cell deposition coupled with high resolution cell imaging. Biotechnol Prog [Internet]. American Chemical Society (ACS); 2015;31(5):1172-8. [10.1002/btpr.2145]

85. Paquet D, Kwart D, Chen A, Sproul A, Jacob S, Teo S, et al. Efficient introduction of specific homozygous and heterozygous mutations using CRISPR/Cas9. Nature. 2016;533(7601):125-9. [10.1038/nature17664]

86. Olive JF, Qin Y, DeCristo MJ, Laszewski T, Greathouse F, McAllister SS. Accounting for tumor heterogeneity when using CRISPR-Cas9 for cancer progression and drug sensitivity studies. Ahmad A, editor. PLoS One. 2018 J;13(6):e0198790. [10.1371/journal.pone.0198790]

87. Shalem O, Sanjana NE, Zhang F, Sciences C. High-throughput functional genomics using CRISPR-Cas9 Ophir. Nat Rev Genet. 2015;16(5):299-311. [10.1038/nrg3899]

88. Doench JG, Hartenian E, Graham DB, Tothova Z, Hegde M, Smith I, et al. Rational design of highly active sgRNAs for CRISPR-Cas9-mediated gene inactivation. Nat Biotechnol. 2014;32(12):1262-7. [10.1038/nbt.3026]

89. Li M, Wu X, Gao J, Yang F, Zhang C, Ke K, et al. Mutations in the P10 region of procaspase- 8 lead to chemotherapy resistance in acute myeloid leukemia by impairing 
procaspase-8 dimerization. Cell Death Dis. 2018; 9(5):516. [10.1038/s41419-0180511-3]

90. Pu X, Storr SJ, Zhang Y, Rakha EA, Green AR, Ellis IO, et al. Caspase-3 and caspase8 expression in breast cancer: caspase-3 is associated with survival. Apoptosis. 2017;22(3):357-68. [10.1007/s10495-016-1323-5]

91. Jaime-Sánchez P, Catalán E, Uranga-Murillo I, Aguiló N, Santiago L, M Lanuza P, et al. Antigen-specific primed cytotoxic T cells eliminate tumour cells in vivo and prevent tumour development, regardless of the presence of anti-apoptotic mutations conferring drug resistance. Cell Death Differ. 2018;1-13. [10.1038/s41418-018-0112-9]

92. Kaiser WJ, Upton JW, Long AB, Livingston-Rosanoff D, Daley-Bauer LP, Hakem R, et al. RIP3 mediates the embryonic lethality of caspase-8-deficient mice. Nature. 2011; 471(7338):368-72. [10.1038/nature09857]

93. Weinlich R, Oberst A, Dillon CP, Janke LJ, Milasta S, Lukens JR, et al. Protective roles for caspase-8 and cFLIP in adult homeostasis. Cell Rep. 2013;5(2):340-8. [10.1016/j.celrep.2013.08.045]

94. Kang T-B, Oh G-S, Scandella E, Bolinger B, Ludewig B, Kovalenko A, et al. Mutation of a self-processing site in caspase-8 compromises its apoptotic but not its nonapoptotic functions in bacterial artificial chromosome-transgenic mice. J Immunol. 2008;181(4):2522-32. [10.4049/jimmunol.181.4.2522]

95. Philip NH, DeLaney A, Peterson LW, Santos-Marrero M, Grier JT, Sun Y, et al. Activity of Uncleaved Caspase-8 Controls Anti-bacterial Immune Defense and TLRInduced Cytokine Production Independent of Cell Death. PLoS Pathog. 2016;12(10):130. [10.1371/journal.ppat.1005910] 